\title{
O Jeca Doente de Problema Vital: Monteiro Lobato e os higienistas de São Paulo em $1918^{1}$
}

\author{
José Wellington SOUZA*
}

RESUMO: Neste artigo, trato da relação de Monteiro Lobato com o movimento Higienista-Sanitarista brasileiro e a consequente mudança de sua definição sobre o homem pobre do campo, que o levou a publicar diversos artigos em defesa da campanha sanitarista, resultando na edição desses artigos sob a forma do livro Problema Vital, de 1918, custeada pela Sociedade Eugênica de São Paulo. A partir de Problema Vital, Jeca Tatu não mais desempenhava o papel da figura emblemática que apresentou em Urupês (1918), mas passa a ser o resultado de infindáveis doenças tropicais passíveis de serem remediadas pelas práticas de higiene, e a literatura lobatiana abandona o caráter literário realista dos primeiros contos, e assume o cientificismo sanitarista, do qual o autor tornou-se espécie de propagandista.

PALAVRAS-CHAVE: Literatura. Higienismo. Eugenia.

\section{Jeca Tatu: o Sertanejo de Monteiro Lobato}

Segundo Lilia M. Schwarcz (1995), na virada do século XIX para o século $\mathrm{XX}$, diversos questionamentos sobre as possibilidades de constituição do Brasil enquanto Estado-nação sólido e viável tornaram-se pauta entre a classe dominante brasileira. Intelectuais, como Arthur de Gobineau, há muito já vinham proclamando a inviabilidade da nação brasileira, inviabilidade dita como consequência direta

\footnotetext{
Universidade Federal de Juiz de Fora. Instituto de Ciências Humanas. Juiz de Fora - MG - Brasil. 36036900 - josewcso@gmail.com.

1 O presente trabalho faz parte das reflexões desenvolvidas em minha tese Raça e Eugenia na Obra Geral de Monteiro Lobato (2017), defendida na Universidade Federal de Juiz de Fora, sob a orientação do Prof. Dr. Dmitri C. Fernandes, e financiada com bolsa de doutorado da FAPEMIG.
} 
da nefasta miscigenação que degenerava a população do país e que teria sido testemunhada pelo próprio autor, na cidade do Rio de Janeiro, durante o breve período em que viveu no Brasil. A sentença de Gobineau era seguida de perto por outros intelectuais, como, por exemplo, Henry Thomas Burkle, que considerava a civilização nos trópicos impraticável, devido às condições climáticas, por Louis Couty, que via na colonização do Brasil pelos africanos a fonte de todos os males do país e que propunha a emigração de colonos europeus como a única solução para a nação, e Louis Agassiz, para quem o Brasil era a prova concreta das consequências disgênicas da miscigenação (SKIDMORE, 1976; STEPAN, 2005).

A problematização do que se convencionou chamar de questão racial, logo tomou a forma de discussões sobre eugenia e disgenia racial, em todas as suas variedades, e reverberou por toda produção intelectual em solo brasileiro, aparecendo de forma privilegiada na literária de Monteiro Lobato, em especial em seus escritos não direcionados às crianças, ao ponto do autor poder ser selecionado como o intelectual adequado para servir de base para um estudo sobre tal fenômeno.

Desde o início de sua produção literária, Monteiro Lobato apresentou uma posição ambígua e vacilante quanto à questão racial, com diversas alterações nos sentidos dados ao termo raça, e nas conclusões derivadas desses sentidos dado ao termo, ao longo das décadas nas quais escreveu sobre o tema e tentou definir a relação entre a constituição fisiológica do homem brasileiro e a repercussão deste homem no futuro da nação.

As preocupações de Lobato sobre a problemática racial já aparecem nas cartas do autor quando este ainda era estudante de direito, numa argumentação que, de certa forma, o coloca como herdeiro da chamada geração de 1870, tendo Lobato encampado posições apresentadas por Sílvio Romero (1954), especialmente sobre Euclides da Cunha. Ainda nos primeiros anos da década de 1910, Lobato reelabora questões raciais advindas da obra de Euclides para definir a condição das sub-raças ${ }^{2}$ esquecidas pela recente República, e trata do drama do caboclo do Vale do Paraíba nos contos que mais tarde fariam parte da coletânea Cidades Mortas (1919/2010), que embora lançada em 1919 trazia artigos datados de 1904 e 1905 (LOBATO, 1944/1972), nos artigos Urupês e Velha Praga, inicialmente publicados no jornal O Estado de São Paulo, em 1912, e mais tarde lançados na primeira coletânea do autor Urupês, de 1918, e principalmente nos contos escritos entre 1914 e 1917 que compõem este primeiro livro do autor (LOBATO, 1944/1972). É especialmente em Urupês, que o autor retomar algumas concepções do homem sertanejo, com certo cunho racial, apresentadas por Euclides da Cunha em Os Sertões (1902/1905).

\footnotetext{
2 Não no sentido de raças inferiores, mas no sentido de variações raciais ainda não completamente definidas e desprendidas das raças, ou misturas raciais, de onde se originam.
} 
Euclides foi um autor muito admirado por Lobato, tanto que em 1907, estando na cidade de Areias, o autor escreveu em uma de suas correspondências a Godofredo Rangel, com indisfarçável entusiasmo, relatando ter dormido no mesmo quarto de pensão que havia abrigado Euclides da Cunha. Sobre suas impressões a respeito da cidade de Areias, Monteiro Lobato ainda escreveu, talvez impressionado pela passagem de Euclides da Cunha por ali, "Areias, Rangel! Isto dá um livro a ${ }^{3}$ Euclides" (LOBATO, 1944/1972, p. 93).

Anos mais tarde, Monteiro Lobato escreveu o artigo "Euclides, um gênio americano" (1933/1968), onde materializa sua admiração por Euclides e o compara a gênios literários universais:

Gênios como Euclides não merecem fins de vida sórdidos. São explosões da Natureza - e devem acabar em explosões. Fiquem para nós outros, "medepalmos", a "aposentadoria" com seus reumatismos, seus pigarros, sua imbecilidade caquética. O premio de Nietzsche foi à loucura. O premio de Shelley foi o afogamento. Num mundo mais mecanizado, como o nosso, está muito bem que o premio de Euclides haja sido uma bala de parabelum no peito (LOBATO, 1933/1968, p. 255).

As inquietações estilísticas de Monteiro Lobato de 1907 até 1917, expostas em suas cartas a Godofredo Rangel, também dão impressão quase palpável de que o objetivo de Monteiro Lobato era mesmo escrever "um livro a Euclides", o que também pode ser percebido na concepção racial que Lobato assume em seus primeiros escritos, (concepção que numa primeira leitura nos passa a impressão de imprecisão, dada a variedade de fatores (como clima, economia, condições históricas etc.) envolvidos em sua definição, mas que definitivamente não podem ser reduzidas a questão da mestiçagem como fazem autores como Skidmore, (1976) e Schwarcz (1995), para citar os destacados ${ }^{4}$, tendo o próprio Jeca Tatu, personificação máxima do tipo humano-literário elaborado por Lobato, sido formado sobre os construtos simbólicos que Euclides havia cunhado para o tipo-literário que criou, o Sertanejo.

As semelhanças entre os dois tipos literários tornam-se explícitas se tomarmos a descrição que Monteiro Lobato faz de seu caboclo e a sobrepormos à certas passagens de Os Sertões, o que se dá especialmente nos trechos, nos quais os autores definem o homem do sertão, em sua dinâmica corporal, segundo seu tipo-literário, o que talvez poderíamos designar, mais sociologicamente, como sendo seu ethos.

Lobato descreve seu caboclo:

\footnotetext{
3 Mantenho aqui, como em outras ocasiões, a acentuação original da obra citada.

4 A complexidade do pensamento racial em Monteiro Lobato no período em questão não pode ser resumida aqui. Sobre esse tema a obra de Araujo (2005) é bastante instrutiva. O mesmo que aplica ao pensamento racial de Euclides da Cunha, que por si só merece um trabalho à parte.
} 
O caboclo continua de cocoras, a modorrar...

Nada o esperta. Nenhuma ferrotoada o põe de pé.

Social, como individualmente, em todos os atos da vida, Jeca, antes de agir, acocora-se. [...].

Ei-lo que vem falar ao patrão. Entrou, saudou. Seu primeiro movimento após prender entre os labios a palha de milho, sacar o rolete de fumo e disparar a cusparada d'esguicho, é sentar-se jeitosamente sobre os calcanhares. Só então destrava a lingua e a inteligência.

— "Não vê que...

De peou sentado as ideias se lhe entramam, a lingua emperra e não ha de dizer coisa com coisa.

De noite, na choça de palha, acocora-se em frente ao fogo para "esquenta-lo", imitado da mulher e da prole.

Para comer, negociar uma barganha, ingerir um café, tostar um cabo de foice, faze-lo noutra posição será desastre infalível. Ha de ser de cocoras.

Nos mercados, para onde leva a quitanda domingueira, é de cocoras, como um faquir do Bramaputra, que vigia os cachinhos de brejaúva ou o feixe de tres palmitos (LOBATO, 1918/1951, p. 244-245).

O que se assemelha muito do que foi dito por Euclides sobre o sertanejo:

Avança celeremente, num bambolear característico, de que parecem ser o traço geométrico os meandros das trilhas sertanejas. E se na marcha estaca pelo motivo mais vulgar, para enrolar um cigarro, bater o isqueiro ou travar ligeira conversa com um amigo, cai logo - cai é o termo - de cocaras, atravessando largo tempo numa posição de equilíbrio instável, em que todo o seu corpo fica suspenso pelos dedos grandes dos pés, sentado sobre os calcanhares, com uma simplicidade a um tempo ridicula e adorável (CUNHA, 1902/1905, p. 114-115) [grifo meu].

A constatação de que Lobato teria escrito Urupês e Cidades Mortas "a Euclides" não é inédita, e já foi efetivada por Luciana Meire da Silva (2013). Segundo a autora, a forma de pensar o homem rural presente em Lobato foi amplamente fundamentada sobre escritos euclidianos, e:

Neste sentido, não podemos deixar de observar no conto "Cidades Mortas", escrito em 1906, ressoam influências dos artigos "Fazedores de Deserto" e "Entre Ruínas", de Euclides da Cunha, escritos em 1901. Talvez pudéssemos dizer, nesse primeiro momento, Monteiro Lobato "imitava" o verbo euclidiano, a começar 
pelo título, a linguagem e o significado da expressão "cidades mortas" muito próxima dos títulos dos artigos de Euclides da Cunha (SILVA, 2013, p. 44- 45).

Em seu trabalho, Silva (2013) ainda chama a atenção para um artigo escrito por Euclides sobre o decadente Vale do Paraíba, em que se critica o uso esterilizante que se fazia da terra naquela região, e que em muito se assemelha ao que posteriormente foi escrito por Monteiro Lobato sobre o interior paulista do início do século passado. De acordo com Silva (2013):

No artigo "Fazedores de Deserto", Euclides da Cunha critica veementemente a crise agrária na região do Vale do Paraíba, e entende que o que a produziu foi o ataque à terra de forma irracional, por parte dos aborígenes, dos bandeirantes, dos sertanejos e dos fazendeiros, prática de queimadas das matas, devastadora e a deixara estéril e degradada, com a argila árida revolvida a céu aberto: "tais selvatiquezas atravessaram toda a nossa história". Euclides critica a agricultura extensiva, pois não permitia períodos de descanso às terras, para reposição do húmus tonificante, era uma atividade predadora ao meio ambiente produtora de infertilidade e irracional porque se constituía em um entrave ao progresso nacional (SILVA, 2013, p. 47).

E mais adiante, a autora destaca outro artigo de Euclides da Cunha sobre a mesma região:

No artigo "Entre as Ruínas", Euclides chama a atenção para o estado de decadência e pobreza da região do Vale do Paraíba, ela se destacara no passado como "o cenário predileto da nossa história". Observa no presente a região se compõe de "traços expressivos de grandezas decaídas", um lugar desabrigado e pobre. Euclides reclama da devastação da natureza expressão do apogeu do café, porque os pés do precioso grão estão lá: "cafezais de 80 anos, ralos e ressequidos". Os antigos caminhos percorridos pelos escravos na lida com os cafezais atestam as "grandezas decaídas", as moradias humildes e esparsas são a imagem do declínio, e os morros desnudos de vegetações, vitimados pelos desmatamentos, com as correntezas das águas das chuvas se enfraquecem porque o solo é levado pelas águas, provoca os desmoronamentos das encostas, processo que acelera o empobrecimento do solo. Nota, ainda, a monotonia do horizonte descampado sem a exuberante natureza (SILVA, 2013, p. 48-49).

Mas, as similaridades entre os autores vão além, e a mesma causalidade multifatorial que envolve em um mesmo complexo, noções muitas vezes pouco 
definidas, de variáveis sociológicas, raciais, climáticas e econômicas que se apresentam na obra de Euclides, são replicadas em Lobato, quando este produz uma problematização literária da personagem do homem caipira, também multifatorial e notadamente sociológica, que o aproxima das construções do realismo moderno, sendo que muito da configuração de seu homem sertanejo (somada à rejeição do autor ao indianismo romântico), pode ser compreendida pelo conceito de criaturidade elaborado por Auerbach, conforme afirma Souza (2017).

Lobato apontava, como causas do atraso e do subdesenvolvimento da região, o café e a economia baseada na monocultura, bem como a estagnação das coisas e dos seres, e considerava a existência de uma unidade de estilo que se estabelecia na relação de harmonia entre o tipo humano e o meio, de forma muito parecida àquela que Auerbach (2009) diz ser própria do realismo moderno, cujo exemplo mais obvio aparece em Balzac que, curiosamente era um dos autores preferidos de Monteiro Lobato.

Sobre a forma que Balzac constrói seu realismo, Auerbach (2009) escreve:

Não parece existir uma ordenação consciente das diferentes retomadas dos motivos da harmonia, assim como não parece que Balzac tivesse seguido um plano sistemático na descrição da aparência de Mme Vauquer; a sequência das coisas mencionadas - cobertura da cabeça, penteado, chinelos, rosto, mãos, corpo, novamente rosto, olhos, corpulência, saiote - não permite reconhecer qualquer traço de composição; também não é indicada nenhuma separação entre roupa e corpo, nem entre um traço físico e o seu significado moral. A descrição toda, até o ponto em que a consideramos, dirige-se para a fantasia mimética do leitor, às imagens lembradas de pessoas semelhantes e de meios semelhantes, que ele possa ter conhecido. A tese da "unidade de estilo" do meio, na qual são também incluídos os seres humanos não é fundamentada racionalmente, mas é apresentada como um estado de coisas imediatamente apreensíveis, de maneira puramente sugestiva, sem provas. Numa frase como esta: ses petites mains potelées, sa personne dodue comme un rat d'église... sont en harmonie avec cette salle où suinte le malheur...et dont Mme Vauquer respire d'air chaudement fétide... pressupõe a tese da harmonia, com tudo o que traz consigo (significação sociológico-moral dos móveis e das peças de vestuário, possibilidade de determinar os elementos ainda não visíveis do meio a partir dos que já foram dados etc.) (AUERBACH, 2009, p. 421).

A tese da "unidade de estilo" ressoa em Lobato, e toma uma forma figurativa de Tapera. A tapera na obra de Lobato é o efeito das "cidades mortas", "dessa coisa chamada interior", do "nosso progresso nômade", que suga a seiva da terra, e parte, deixando atrás de si um "rastilho de taperas". Mas, embora nomeie essa "condição": 
Lobato não distingue as barreiras entre a tapera nas coisas e a tapera nas almas, sendo que uma vem implicar em outra. A tragédia oriunda de causas materiais que se abate sobre as personagens e que levam à "taperização das almas" repercute sobre as condições materiais, levando ao ruir da casa e ao abandono do terreiro às pragas e ao mato. Esse terreiro é tomado por Lobato como sinônimo de mente ou intelecto, o qual pode ser cultivado ou, por outro lado, tomado pelo mato, "com pés de joás, erva de Santa Maria, cordão-de-frade e guanxumas no terreirinho outrora tão limpo" (SOUZA, 2017, p. 55).

Tal apropriação criatural e realista do homem rural, cristalizado no Jeca Tatu, foi, entretanto, deixada de lado por Lobato quando ele se filiou ao Movimento Sanitarista e passou a estabelecer que a doença era o elemento explicativo fundamental da condição trágica do caboclo. A disgenia da raça, causada por fatores sociais e ambientais, de acordo com a genética francesa neolamarckiana, passa ser a chave de leitura para explicar o caboclo e, de forma mais ampla, o homem pobre do campo.

\section{Lobato e os higienistas}

Lançado pela primeira vez em 1918, o livro Problema Vital traz uma série de artigos nos quais Monteiro Lobato elogia o movimento sanitarista no Brasil. Em sua reedição de 1968, em Obras Completas de Monteiro Lobato, (lançado junto de Mister Slang e o Brasil e Problema Vital) uma nota de esclarecimento denota a profundidade das relações que o autor havia travado com os responsáveis pelo movimento eugenista no Brasil. Segundo a nota, a $1^{\mathrm{a}}$ edição deste livro é de 1918 e trazia o seguinte esclarecimento: “Artigos publicados n'O Estado de São Paulo, e enfaixados em volume por decisão da "Sociedade de Eugenia de S, Paulo" e da "Liga Pró-Saneamento do Brasil". (LOBATO, 1918/1927/1968, p. 221)5.

A ligação de Monteiro Lobato com os higienistas de São Paulo, que levou a produção e publicação dos artigos que compõem Problema Vital coincide com a época em que Monteiro Lobato tornou-se editor em São Paulo, quando procurava se inteirar dos movimentos políticos e sociais da cidade (CAVALHEIRO, 1962), e ao aproximar-se do higienismo, levado a cabo por médicos empenhados em uma campanha que visava o controle de doenças e que, segundo acreditavam, incapacitavam o homem brasileiro de fazer do Brasil uma grande nação, que só seria possível com uma população nacional eugênica, Lobato passou a fazer parte de um dos grandes projetos de reforma política na Primeira República, conforme

5 A acentuação reproduzida nas citações segue a gramática oficial da época de lançamento das obras. 
Nancy Stepan considera ter sido o movimento Higienista no Brasil (STEPAN, 2005).

Antes de tratar da relação de Lobato com o movimento higienista brasileiro, entretanto, é preciso desfazer alguns equívocos quanto a sua constituição e propósito, muitas vezes reduzido à sua vertente darwinista e mais que isso, à versão que o nazismo fez do pensamento eugenista. Um exemplo do uso inadequado do termo pode ser encontrado no artigo de Eisenberg, Feres Junior e Nascimento (2013), no qual os autores tratam o racismo em Monteiro Lobato. Segundo a definição dos autores:

Eugenia, palavra que em grego significa "bem nascer", é uma ideologia que tem como base o projeto do melhoramento racial da espécie ou de grupos humanos por meio de seu controle reprodutivo, manipulando características fenotípicas, genéticas e psicológicas para tal fim. Historicamente influenciada pelo evolucionismo surgido na segunda metade do século XIX, particularmente o darwinismo social, tal ideologia atingiu grande popularidade na Europa e nos Estados Unidos nas primeiras décadas do século XX, e foi também recebida no Brasil. Com o advento da Segunda Guerra Mundial, e a derrota do projeto eugenista nazista, perdeu grande parte de seu apelo. Para a história geral dessa doutrina ver Carlson (2001). Para sua recepção no Brasil, ver Stepan (1991). (EISENBERG; FERES JUNIOR; NASCIMENTO, 2013, p. 101).

Entretanto, segundo a Nancy Stepan (2005), a eugenia defendida pelo movimento higienista em voga no Brasil daquele período estava baseada numa biologia neolamarckiana, uma teoria sobre a hereditariedade derivada da teoria lamarckiana, e que considera a possibilidade de que caracteres adquiridos ao longo da vida pelos progenitores pudessem ser transmitidos aos descendentes. Nessa perspectiva, nutrir e curar uma geração adoentada pode favorecer as novas gerações e, consequentemente, melhorar a raça, promovendo a eugenia, o que a diferenciava radicalmente da concepção de hereditariedade genética weismann-mendeliana, concepção biológica segundo a qual o meio não interferia na carga genética do indivíduo, cujas características eram racialmente determinadas. De acordo com Stepan (2005) é notável a predominância entre os higienistas brasileiros da vertente biologicista francesa, e consequentemente das teorias eugenistas neolamarkianas, em detrimento do tipo de eugenia "germânica" ou eugenia "anglo-saxã" de base mendeliana, o que segundo a autora fazia uma grande diferença:

(...) os eugenistas brasileiros baseavam sua eugenia não na concepção mendeliana da genética, a estrutura dominante na Grã-Bretanha, nos Estados Unidos e na 
Alemanha, mas em uma corrente alternativa de noções neolamarckianas de hereditariedade. Esse estilo de eugenia refletia conexões científicas de longa data com a França, bem como fatores mais locais de cultura política; ajudava também a estruturar os debates sobre degeneração e determinava como a nova genética e as ciências do saneamento interagiriam de forma inovadora na "eugenia" (STEPAN, 2005, p.14).

As consequências mais evidentes do predomínio da vertente neolamarckiana entre os brasileiros foram à constituição das políticas de saneamento e higienização, uma vez que estas eram tidas como formas legítimas de promover a eugenia, sendo esse termo considerado sinônimo da política higienista, entre os profissionais de saúde nacionais.

Daí, por exemplo, a insistência de Olegário de Moura, vice-presidente da Sociedade Eugênica de São Paulo, em dizer que "sanear é eugenizar". Ele afirmava que saneamento era a mesma coisa do que algumas pessoas chamavam eugenia, (...) apesar de a palavra "eugenia" ser "cientificamente" melhor. Ele próprio fazia a correspondência entre as duas da seguinte maneira: "Saneamentoeugenia é ordem e progresso" (STEPAN, 2005, p. 93).

Dessa forma, a exemplo do que aconteceu na França, houve no Brasil atuações de organizações em prol do saneamento, movimento de forte vertente nacionalista que via em suas ações as bases de constituição de uma nação civilizada. Nesse sentido, Stepan (2005) argumenta que:

(...) a eugenia lamarkiana conquistou aliados no movimento em prol do saneamento rural, como Belisário Penna, cuja longa viagem a cavalo, em 1912, entre as populações doentes dos estados do Nordeste brasileiro fez com que encetasse uma cruzada em prol da saúde rural. Como sogro de Kehl, que veio a ser, a adesão de Penna foi extremamente útil e estratégica para a eugenia, permitindo-lhe conquistar o apoio dos higienistas que pensavam como ele. Outros aliados foram recrutados entre as ligas nacionalistas e pró-saneamento que brotaram no Brasil antes e depois da Primeira Guerra Mundial. As relações de seus respectivos membros e os estilos e discursos da Liga Nacionalista de São Paulo e da Sociedade Eugênica de São Paulo tinham consideráveis superposições (STEPAN, 2005, p. 98).

É importante notar que durante a República Velha, especialmente a partir da publicação de Os Sertões (1902/1905) de Euclides da Cunha, as condições 
precárias dos homens do sertão apareceram como um dos maiores desafios para a viabilidade nacional, transformada em preocupação médica, principalmente após a expedição exploratória de Miguel Pereira e Belisário Penna, cujos resultados foram publicados em artigos de jornal e mais tarde encadernados no livro Saneamento do Brasil, de Belisário Penna (1918/1923). Tal diagnóstico ressoava ainda pelas vozes de Oswaldo Cruz, Carlos Chagas, Álvaro Osório de Almeida, Belisário Penna e Arthur Neiva, alguns dos homens mais relevantes para a República (STEPAN, 2005).

Dentre os higienistas, Lobato parece ter tido maiores contatos e afinidades com o médico Renato Kehl, que após clinicar em São Paulo por alguns anos, aproximou-se do Movimento Sanitarista e da eugenia. Foi Kehl quem fundou, em 1918, a Sociedade Eugênica de São Paulo, e foi também responsável por diversos boletins, livros e panfletos, nos quais divulgava e discutia os princípios da eugenia.

A consideração de Lobato por Kehl ficou registrada em uma carta escrita por Lobato em 1918, cujo trecho reproduzo a seguir:

Acabo de ler sua conferência sobre eugenia, lida na A. C. de M. e confesso-me envergonhado por só agora travar conhecimento com um espírito tão brilhante como o teu, untado para tão nobres ideais e servido, na expressão do pensamento, para um estilo verdadeiramente 'eugênico' pela clareza, equilíbrio e rigor vernacular (LOBATO, 1918 apud HABIB, 2007, p. 1).

Não podemos perder de vista, entretanto, que a conversão de Lobato ao movimento higienista não se limitou apenas a afinidade pessoal ou ideológica com os médicos eugenistas. Ao escrever sobre o sanitarismo, Lobato conseguiu ter acesso a um público leitor formado por médicos e outros profissionais de saúde, assim como conquistou o patrocínio para a publicação de Problema Vital, e pode compartilhar do prestígio social alcançado pelos sanitaristas à época.

Deu-se então uma grande virada no pensamento racial de Monteiro Lobato, que então assumiu uma clara perspectiva racialista, só que em termos neolamarckianos, que para Lobato passaram a explicar os danos causados pela doença de Chagas e outras moléstias que corroíam os indivíduos, e que passaram a explicar o "porque e como dos Fernões Dias Pais Leme de outrora, terríveis varões enfibrados de aço, ressurgiu uma geração aventada, anemiada, feia e incapaz. [E concluía] Não é a raça - a raça dos bandeirantes é a mesmas de Jeca Tatu" (LOBATO, 1918/1968, p. 305-306), e da mesma forma pôde fazer a famosa afirmação de que "O Jeca não é assim: está assim". 


\section{Um microscópio sobre o Problema Vital}

Após afirmar o estado transitório do Jeca, o primeiro artigo que aparece em Problema Vital (LOBATO, 1918/1968) e A ação de Osvaldo Cruz (LOBATO, 1918/1968), Lobato critica o ufanismo ingênuo da elite brasileira, pautado na "tríplice miragem", que teria como alicerces as seguintes afirmações: a de que "somos um dos povos mais inteligentes e sensatos do Mundo", somadas a de que "Somos o país mais rico do mundo" (Lobato, 1918/1968, p. 223) e de que "O Brasil é o único país que, além do Japão, jamais foi vencido em uma guerra...”. Após essas pontuações, Lobato restringe o alvo ao campo literário e aos poetas responsáveis por apregoar as maravilhas da terra materna, fazendo críticas muito parecidas às feitas contra o escritor romântico que descrevia o Brasil de forma idílica e desprovida de realismo, conforme o fizeram, segundo a crítica Lobatiana: "Cardumes de poetas menores - desses para quem em sua republica Platão Legislava: Coroai-os de rosas e expulsai-os - por sua vez puseram em verso a grande ilusão, de modo a perpetua-la pela mnemônica da rima e do metrona cabeça fraca do povo" (LOBATO, 1918/1968, p. 224).

Adiante, o autor comenta as supostas maravilhas de nossa pátria sob os prismas literários ufanistas:

Riqueza. Te-la no seio da terra, no azoto do ar, nas essencias florestais, na literatura côr de rosa e não te-la sonante no bolso, é ser nabado á moda do chinês em transe megalomaníaco se sonho d'opio. A noção economica de riqueza, desde Adam Smith, é um poucochinho diversa - a mesma diversidade que vai da palavra libra-esterlina á rodelinha amarela chamada libra-esterlina (LOBATO, 1918/1968, p. 225).

Após apontar as críticas, Lobato aponta a nomeação de Osvaldo Cruz para chefe da higiene no Rio de Janeiro como marco para a reconstrução do Brasil. Com ele, teria vindo para o país a ciência moderna de Pasteur e da microbiologia. Sem pudores, Lobato elogia a ação dos cientistas sediados em Manguinhos (Belisário Pena, Carlos Chagas e Arthur Neiva) e a revolução do microscópio, o qual poderia livrar o Brasil de suas mazelas. Por fim, apresenta o livro de Belisário Penna, O Saneamento do Brasil (1918/1923), como marco denunciador de um Brasil esquecido:

(...) voz de sábio que escarna ao vivo as mazelas do país idiotizado, exangue, leishmanioso, papudo, faminto na proporção de 80 por cento, e grito de indignação dum homem de bem contra a ftiríase organizada em sistema político que roi com fúria acarina o pobre organismo inanime (LOBATO, 1918/1968, p. 229). 
O artigo seguinte é intitulado Dezessete milhões de opilados (LOBATO, 1918/1968). Segundo os dados apresentados no texto, de uma população de 25 milhões de habitantes, 17 milhões sofriam de ancilostomose. Lobato explica superficialmente (em um texto claramente direcionado para leigos) as características fisiológicas e reprodutivas dos vermes causadores do popularmente chamado "mal da terra" ou amarelão. Depois de descrever o verme e sua ação, compara-o (em um breve adendo) a um parasita que se acosta em ócio ao Estado, para sorver o sangue-dinheiro elaborado pelas classes produtoras (LOBATO, 1918/1968, p. 232). Descreve os efeitos maléficos do verme no organismo, da anemia, do prejuízo sobre o "tonus vital", a inclinação "ao vício da cachaça, lenitivo a que recorre para combater a permanente sensação de frio que o desequilíbrio sanguíneo acarreta" (LOBATO, 1918/1968, p. 223).

Lobato faz um curioso jogo duplo que tende a se repetir nos artigos seguintes, a crítica ferrenha à produção literária brasileira de cunho não realista, com seus heroicos sertanejos, crítica semelhante a que fez nos contos que compõem Urupês, embora sem a profundidade criatural que havia dado ao drama do caboclo, que em Problema Vital é reduzido ao drama do sertanejo opilado.

Ademais, segundo as teorias defendidas por Lobato, de que adiantariam problematizações sociológicas sobre as condições de existência do homem do campo chamado de caboclo, assim como as propostas políticas da época de revisão constitucional, o voto feminino, o serviço militar obrigatório ou as reformas parlamentaristas se a guerra definitiva pelo futuro do Brasil era travada em fantásticos combates micro-orgânicos?

Lobato também trata como secundária a questão da imigração para o Brasil, questão elencada por Thomas E. Skidmore (1976, p. 154-162) como ponto central para os intelectuais brasileiros que pretendiam branquear a população brasileira, num projeto chamado pelo brasilianista de tese do branqueamento. Lobato, entretanto, alheio ao que afirma Skidmore (1976) sobre demais intelectuais do período, não apresenta a imigração como solução definitiva para o problema racial brasileiro, uma vez que a falta de trabalhadores aptos é tida por ele como produto de infecções parasitárias que desconhecem fronteiras raciais. O problema, para Lobato, era outro.

É que os braços estão aleijados.

Há-os de sobra, mas ineficientes, de músculos roídos pela infecção parasitaria. O que obriga a lavoura ao ônus indireto de importar músculos europeus, ou chineses, ou japoneses - o que haja, contanto que seja carne sadia e não fibras em decomposição.

Entretanto, a solução definitiva do problema eterno da lavoura quem a dará é a higiene (LOBATO, 1918/1968, p. 242-243). 
Por fim, Lobato conclui que, mais do que qualquer outra coisa, é preciso sanear o Brasil. No artigo subsequente, é apresentada a última doença a devastar o país: Dez milhões de impaludados.

O Brasil é o país mais rico do mundo, diz com entono o Pangloss indígena. Em parasitos hematófagos transmissores de molestias letais - conclui Manguinhos.

E é. Não bastasse o anciolostomo. Não bastava o barbeiro. Vem completar a trindade infernal a anafelina, mosquito que veicula o hematozoario de Laveran, pai da Malária (LOBATO, 1918/1968, p. 247).

Repetidamente, Lobato critica a posição da elite brasileira, especialmente por parte dos literatos ufanistas que retratam o Brasil como um paraíso nos trópicos, mas não aponta a multiplicidade racial como a responsável pela condição deplorável do povo brasileiro. Os trechos que seguem nos indicam outro caminho:

O quinto país do mundo em tamanho a cair aos pedaços, de verminosa lazeira, vendo, ao norte, o maravilhoso surto americano, e ao sul, a pujante floração argentina. E para suprema vergonha e desdouro eterno do nome brasílico, com a consciencia ${ }^{6}$ de que desmedrou arrastado por males evitáveis e de facil cura. Males de que todos os paises de mesologia semelhante se libertaram pela profilatica inteligência, com lentidão uns, com rapidez fulgulrante outros.

Aí está Cuba, a pobre ilha degradada em rápida consumpção por molestias irmãs as nossas e que em poucos anos, ao influxo da higiene norte-americana, virou a maravilha que todos sabemos (LOBATO, 1918/1968, p. 257).

Higiene e sanitarismo são, portanto, o eixo que coordena os textos escritos por Lobato nesse período, assim como são a solução para a raça (no singular) corroída pela fome e pelos vermes.

Ao considerar os problemas raciais como flagelos referentes ao grande número de doentes nos sertões, Lobato estabelece uma nova plataforma para a discussão racial no Brasil, e passa ao problema como sanitário-racial, por meio de uma perspectiva biológico-racial até então inédita:

Imagine-se agora que a ação desses parasitas é ininterrupta, começa na infancia e prolonga-se até á morte.

As lesões que eles praticam nas paredes intestinais, ulcerando-as, funcionam como outras tantas portas abertas ao livre transito das toxinas. 6 Lembro ao/a leitor/a que a "ausência" de acentuação se deve as regras gramáticas observadas na
edição citada. 


\section{José Wellington Souza}

O pai dessa pobre criatura já foi um bichado, como o foi o avô e o bisavô. Deles recebeu ela uma vitalidade menor, uma tonicidade orgânica decaída, um indice de defesa natural. E por sua vez transmitirá ao filho a má herança acrescida funestamente da sua contribuição pessoal de degenerescencia, consecutiva á continuação do trabalho do verme em seu organismo.

Isto explica porque e como dos Fernões Dias Pais Leme de outrora, terríveis varões enfibrados de aço, ressurgiu uma geração aventada, anemiada, feia e incapaz.

Não é a raça - a raça dos bandeirantes é a mesma de Jeca Tatu. É um longo e ininterrupto estado de doença transmitida de pais a filhos e agravado dia a dia.

Examinando-lhe o sangue, assombra a pobreza em hemogrobinas: não é mais sangue o que lhes corre nas veias, senão um aguado soro. E nessa suja, para remate dos males, ainda vem aboletar-se o protozoário da malaria... (LOBATO, 1918/1968, p. 305-306) [grifo meu].

Definitivamente, nos textos de Problema Vital a degenerescência em questão se trata da degeneração da raça em sua totalidade, e não das sub-raças substancialmente deterioradas pela mestiçagem. A raça dos grandes desbravadores bandeirantes é, segundo Lobato, a mesma do Jeca Tatu, deteriorada pela doença e pelas verminoses, e a degenerescência racial se dá a partir da transmissão hereditária de tonicidade e vitalidade insuficientes - de um "bisavô bichado" para um "avô bichado" e assim sucessivamente -, déficits devidos às infecções parasitárias adquiridas e transmitidas, somada à própria degenerescência do indivíduo.

"Não é a raça", não no sentido darwinista ou mendeliano, a responsável pela decadente condição física e mental do indivíduo; mas é a raça no sentido de características assimiladas e legadas aos descendentes, ou seja, a raça no sentido neolamarkiano do termo.

O último texto que compõe Problema Vital é Jeca Tatu: a ressurreição, o qual, como o título sugere, demonstra a possibilidade de ressurreição do Jeca, que representa a ressurreição potencial da raça. A Ressurreição começa por descrever o Jeca e as condições de vida que o cercam:

Jeca Tatu era um pobre caboclo que morava no mato, numa casinha de sapé (...) passava os dias de cócoras, pitando enormes cigarrões de palha, sem ânimo de fazer coisa nenhuma. Ia ao mato caçar, tirar palmitos, cortar cachos de brejaúva, mas não tinha idéia de plantar um pé de couve atrás da casa (LOBATO, 1918/1968, p. 329). 
O Jeca Tatu de Problema Vital é uma espécie de bricolagem das personagens apresentadas em Urupês. A economia extrativista, o banquinho de três pernas, a espingardinha de carregar pela boca e o cachorrinho magro e cheio de bernes a acompanhar o dono bêbado reaparecem aqui para definir o Jeca e seu modo de vida. Apesar disso, não é o meio descrito que é simultaneamente causa e consequência da desgraça do caboclo, como acontece nos contos de Urupês, mas um problema de saúde pública, pois o Jeca é, antes de tudo, um doente. E assim segue, até que:

Um dia um doutor portou lá por causa da chuva e espantou-se de tanta miséria. Vendo o caboclo tão amarelo e chucro, resolveu examiná-lo.

_ Amigo Jeca, o que você tem é doença.

_ Pode ser. Sinto uma canseira sem fim, e dor de cabeça, e uma pontada aqui no peito que responde na cacunda.

_ Isso mesmo. Você sofre de anquilostomiase (...) (LOBATO, 1918/1968, p. 331-332).

Uma vez diagnosticado o mal que afligia o Jeca, o doutor, membro individual do corpo coletivo dos sanitaristas, receita o remédio e a técnica que livraram o pobre homem da miséria.

O doutor receitou-se o remédio adequado; depois disse: "E trate de comprar um par de botinas e nunca mais me ande descalço nem beba pinga, ouviu?’[...].

Faça o que mandei, que ficará forte, rijo e rico como o italiano. (LOBATO, 1918/1968, p. 332).

E o Jeca curado faz uso das técnicas da "Nhá Ciência" para manter-se saudável, produtivo e empreendedor.

Quando o doutor reapareceu, Jeca estava bem melhor, graças ao remédio tomado. O doutor mostrou-lhe com uma lente o que tinha saído das suas tripas.

_Veja, sêo Jeca, que bicharia tremenda estava se criando na sua barriga! São os tais anquilostomos, uns bichinhos dos lugares úmidos, que entram pelos pés, vão varando pela carne adentro até alcançarem os intestinos (...) (LOBATO, 1918/1968, p. 333).

[...]

Mas Jeca não podia acreditar numa coisa: que os bichinhos entrassem pelo pé. Ele era "positivo" e dos tais que "só vendo". O doutor resolveu abrir-lhe os olhos. Levou-o a um lugar úmido, atrás da casa, e disse: 
- Tire a botina e ande um pouco por aí.

Jeca obedeceu.

Agora venha cá. Sente-se. Bote o pé em cima do joelho. Assim. Agora examine a pele com esta lente.

Jeca tomou a lente, olhou e percebeu vários vermes pequeninos que já estavam penetrando na sua pele, através dos poros. O pobre homem arregalou os olhos assombrado.

_E não é que é mesmo? Quem "haverá" de dizer!...

_ Pois é isso, sêo Jeca, e daqui por diante não duvide mais do que a ciência disser.

_ Nunca mais! Daqui por diante Nhá Ciência está dizendo e Jeca está jurando em cima! T'esconjuro! E pinga, então, nem p'ra remédio... (LOBATO, 1918/1968, p. 333-334).

Salvo de todos os males, mas destituído da complexidade socioeconômica que o constituem na vida, o caipira é definitivamente salvo pela técnica médica e higienista. Ao deixar de duvidar da ciência, e começar a medicar-se e tomar medidas profiláticas como o uso de botinas, o Jeca ressurge, como que renascendo de suas próprias cinzas, na forma de um novo ser social capaz de proezas até então inimagináveis.

Tudo o que o doutor disse aconteceu direitinho! Três meses depois ninguém mais conhecia o Jeca.

A preguiça desapareceu. Quando ele agarrava no machado, as árvores tremiam de pavor. (...) Jeca, cheio de coragem, botou abaixo um capoeirão para fazer uma roça de três alqueires (...) consertou todos os buracos da casa. E fez um chiqueiro para os porcos. E um galinheiro para as aves (...) (LOBATO, 1918/1968, p. 334).

E livre das doenças que o consumiam, graças aos medicamentos e as técnicas de higiene, o Jeca acaba por transmutar-se em dedicado trabalhador e, por fim, em empreendedor e empresário capitalista.

(...) Comprou arados e bois, e não plantava nada sem primeiro afofar a terra.(...).

E Jeca já não plantava rocinhas como antigamente. Só queria saber de roças grandes, cada vez maiores, que fizessem inveja no bairro.

E se alguém lhe perguntava:

_ Mas para que tanta roça, homem? Ele respondia: 
_É que agora quero ficar rico. Não me contento com trabalhar para viver. Quero cultivar todas as minhas terras, e depois formar aqui uma enorme fazenda. E hei de ser até coronel... (...) (LOBATO, 1918/1968, p. 336).

Por fim, o Jeca norte-americaniza-se em um processo pelo qual as complexidades culturais, históricas e econômicas das civilizações norte-americana e brasileira são reduzidas a estereótipos que, em última instância, são determinados por causas biológicas, de forma que o homem biologicamente saudável, livre dos elementos patógenos, se transforma, naturalmente, no homem economicamente fordista:

Jeca adquiriu um caminhão Ford, e em vez de conduzir os porcos ao mercado pelo sistema antigo, levava-os de auto, num instantinho, buzinando pela estrada afora, fon-fon! fon-fon!...

As estradas eram péssimas; mas ele consertou-as à sua custa. Jeca parecia um doido. Só pensava em melhoramentos, progressos, coisas americanas. Aprendeu logo a ler, encheu a casa de livros e por fim tomou um professor de inglês (LOBATO, 1918/1968, p. 337).

\section{$[\ldots]$}

A fazenda do Jeca tornou-se famosa no país inteiro. Tudo ali era por meio do rádio e da eletricidade. Jeca, de dentro do seu escritório, tocava num botão e o cocho do chiqueiro se enchia automaticamente de rações muito bem dosadas. Tocava outro botão, e um repuxo de milho atraia todo o galinhame...

Suas roças eram ligadas por telefones. Da cadeira de balanço, na varanda, ele dava ordens aos feitores lá longe.

Chegou a mandar buscar nos Estados Unidos um telescópio. (LOBATO, 1918/1968, p. 338-339).

O ápice dessa peça de propaganda se dá quando, no parágrafo XVII, já rico e estabelecido, o Jeca retribui o bem que lhe foi feito pela "Nhá Medicina", montando Postos de Maleita e Postos de Anquilostomose na fazenda e nas vilas. Dessa forma, enfatiza claramente que a campanha sanitarista é a maneira verdadeiramente patriótica de se salvar o Brasil, assim como destaca o dever do cidadão de contribuir para essa campanha. Fica clara, nesse ponto, a submissão do campo literário e do autor ao polo dominante das políticas públicas sanitaristas, das quais era quase um porta-voz (LOBATO, 1918/1968, p. 339-340). 


\section{Considerações finais}

Por fim, é importante ressaltar que a afinidade existente entre Lobato e os sanitaristas, originada na mesma visão que esses tinham da condição do homem do campo e do Sertão, esteve pautada na adesão de Lobato às posições dos médicos sanitaristas que se redobravam em avaliações literárias sobre o homem do campo, sobreposição reafirmada por autores que estudam diretamente a história do sanitarismo no Brasil, como, por exemplo Lima e Hochman (2000):

Os médicos Belisário Penna e Arthur Neiva ressaltam o contraste entre a retórica romântica sobre o caboclo e o sertanejo e o que observam e relatam. A descrição real era de um povo ignorante, abandonado, isolado, com instrumentos primitivos de trabalho, desconhecendo o uso da moeda, tradicionalista e refratário ao progresso. Esse quadro de isolamento era responsável pela ausência de qualquer sentimento de identidade nacional. Um povo que desconhecia qualquer símbolo ou referência nacional, ou melhor, "a única bandeira que conhecem é a do divino" (NEIVA; PENNA, 1916 apud LIMA; HOCHMAN, 2000, p. 500).

Nesse processo, fazendo frente ao entusiasmo dos românticos em relação à figura do caboclo, Monteiro Lobato deu maiores cores à falta de saúde deste, nos artigos que compõem Problema Vital -, apesar de, no processo, reduzir parte considerável da complexidade da condição social do homem abandonado no interior decadente de São Paulo, presentes em sua obra prescedente.

\section{Sick Jeca in Problema Vital: Monteiro lobato aNd the hygienists of São PaUlo IN 1918}

ABSTRACT: In this paper, I deal with the relationship between Monteiro Lobato and the Brazilian Hygienist-Sanitarian movement, as well as the consequent change in the author's definition of the poor country man. This relationship led him to publish several papers supporting the sanitary campaign, finally resulting in the collection of these articles under the title Problema Vital, which appeared in 1918, and whose publication was financed by the Eugenic Society of São Paulo. Starting with Problema Vital, Jeca Tatu ceased playing the role of the emblematic figure he appeared as in Urupês (1918), becoming instead the result of endless tropical diseases that could be remedied by hygienic practices. From thence, Lobatian literature abandons the literary realism characteristic of its first stories, and adopts sanitary scientism, of which the author became a sort of propagandist.

KEY WORDS: Literature. Hygiene. Eugenics. 


\section{REFERÊNCIAS}

ARAÚJO, Ricardo Benzaquen. Guerra e Paz: Casa Grande e Senzala e a obra de Gilberto Freyre nos anos 30. São Paulo: Editora 34, 2005.

AUERBACH, Erich. Mimeses: a representação da realidade na literatura ocidental. São Paulo: Perspectiva, 2009.

CUNHA, Euclides. Os Sertões: Campanha de Canudos. Rio de Janeiro- São Paulo: Laemmert \& C. 1905. [1902].

CAVALHEIRO, Edgard. Monteiro Lobato, Vida e Obra. São Paulo: Editora Brasiliense, 1962. 2v.

EISENBERG, Zena Winona; FERES JUNIOR, João; NASCIMENTO; Leonardo Fernandes. Monteiro Lobato e o Politicamente Correto. DADOS - Revista de Ciências Sociais, Rio de Janeiro, vol. 56, no 1, pp. 69 a 108, 2013.

HABIB, Paula Arantes Botelho Briglia. Saneamento, Eugenia e Literatura: Os Caminhos Cruzados de Renato Kehl e Monteiro Lobato.(1914-1926). ANPUH -. XXIV SIMPÓSIO NACIONAL DE HISTÓRIA, - São Leopoldo, 2007.

LIMA, N. T.; HOCHMAN, G. Pouca saúde, muita saúva, os males do Brasil são... Discurso médico-sanitário e interpretação do país. Ciência \& Saúde Coletiva, v. 5 n², pp, 313 a 332, 2000.

LOBATO, Monteiro. A Barca de Gleyre. São Paulo: Editora Brasiliense, 1972.

, Cidades Mortas. São Paulo: Editora Globo, 2010. [1919].

, Na Antevéspera. São Paulo: Editora Brasiliense, 1968. [1933].

, Mister Slang e o Brasil e Problema Vital. São Paulo: Editora. Brasiliense, 1968. [1927]; [1918].

, Urupês. São Paulo: Ed. Brasiliense, 1951. [1918].

PENNA, Belisário. Saneamento do Brasil. Rio de Janeiro: Jacinto Ribeiro dos Santos, 1923. [1918].

SILVA, Luciana Meire da. O Brasil Rural nas obras de Monteiro Lobato nas décadas de 1910 a 1930. 2013. 180 f. Tese (Doutorado em Ciências Sociais)- Universidade Estadual Paulista "Julio de Mesquita Filho", Marília, 2013.

SOUZA, José Wellington de. Raça e Eugenia na Obra Geral de Monteiro Lobato. 2017. 177 f. Tese (Doutorado em Ciências Sociais)- Universidade Federal de Juiz de Fora, Juiz de Fora, 2017. 
SCHWARCZ, Lilia Moritz. O espetáculo das raças: cientistas, instituições e questão racial no Brasil (1870-1930). São Paulo: Companhia das letras, 1995.

ROMERO, Silvio. Contos Populares do Brasil. Rio de Janeiro: José Olympio, 1954.

SKIDMORE, Thomas E. Preto no branco: raça e nacionalidade no pensamento brasileiro. Rio de Janeiro: Editora Paz e Terra,1976.

STEPAN, Nancy Leys. A Hora da Eugenia: Raça, Gênero e nação na América Latina. Rio de Janeiro: Editora Fiocruz, 2005.

Recebido em 22/01/2018.

Aprovado em 19/05/2018. 